\title{
Ventilatory Function Response to Upper Versus Lower Limbs Aerobic Training in Elderly Men
}

\author{
HADEER KAMAL, M.Sc.*; AZZA ABDELAZIZ, Ph.D.*; YOUSSEF MOHAMMED, M.D.** and \\ MARWA M. ELSAYED, Ph.D.*
}

The Department of Physical Therapy for Cardiovascular, Respiratory Disorders and Geriatrics, Faculty of Physical Therapy, Cairo University* and Internal Medicine Department, Faculty of Medicine, Cairo University**

\begin{abstract}
Background: Ventilatory function and aerobic capacity each decline by $\sim 40 \%$, with aging leading to ventilatory limitation, dyspnea, exercise intolerance, which affected by performance of upper and lower limbs, so it is important in the elderly to use aerobic training to improve ventilatory function, by training upper limbs as well as lower limbs which not investigated previously.
\end{abstract}

Aim of Study: To compare between the impact of upper versus lower limbs training on ventilatory function in elderly men.

Material and Methods: Eligible 40 elderly men their age ranged from (60-65) years old, body mass index (BMI) ranged from 25 to $34.9 \mathrm{~kg} / \mathrm{m}^{2}$ participants were recruited from the Outpatient Clinic of Faculty of Physical Therapy, Cairo University, Egypt. Patients were divided into two groups equal in number; the group (A) performed upper limbs training by arm ergometer, while the group (B) performed lower limbs training by cycle ergometer for three times per a week for 12 weeks. Ventilatory function included (Forced expiratory volume in the first second (FEV1), forced vital capacity (FVC), and FEV1/FVC ratio) were evaluated pre and post intervention for 12 weeks (36 sessions).

Results: After 12 weeks of intervention, both groups demonstrated significant increase of FEV 1 and FVC $(p<0.05)$ by contrast there was no significant difference was observed in the mean of FEV1/FVC ratio between pre and postintervention $(p>0.05)$ in both groups.

Conclusion: The results demonstrated that moderate intensity aerobic exercise using both arm ergometer and cycle ergometer has equally effect on improvement of the ventilatory function of elderly men.so we recommended aerobic training of upper limbs as an integral intervention in pulmonary rehabilitation program of elderly subjects.

Key Words: Elderly men - Ventilatory function - Arm ergometer-Cycle ergometer.

Correspondence to: Dr. Hadeer Kamal, E-Mail: h.elhashash @yahoo.com

\section{Introduction}

AS aging progress, the respiratory system undergoes a measurable decline in the physiologic function. The thoracic cage stiffens with advancing age; with the increased possibility for increased kyphosis coupled with increased work demand of the respiratory muscles thus increases the work of breathing. There are significant changes in the functions of the pulmonary system including: Decreased FEV1, FVC and VC, increased RV, and increased FRC [1]. The percent of older people "defined as 60 years of age and more" is $9.2 \%$ in 2021 , and it is expected to reach $20.8 \%$ in 2050. In Egypt is expected to maintain the highest rank in absolute numbers in both old and oldest populations in the region, in 2050 Egypt is expected to have the largest number of old (23.7 million) and oldest old (3.1 million) populations in the region [2] increase in life expectancy, due to better health care, which has led to increase percent of aging [3], associated with increase of percent of many diseases [4], and deterioration in function of many of body systems in healthy ageing, such as between the ages of 25 and 80 years ventilatory function and aerobic capacity each decline by near half of its value, healthy nonsmokers lose approximately $30 \mathrm{~mL}$ of their forced expiratory volume in 1 second (FEV 1) every year beginning after 30 years of age especially in men [5]. Also the forced vital capacity (FVC) decreases with aging, there is an accelerated decline in both FEV1 and in FVC between 60 and 93 years of age [6].

FVC, FEV1, and ratio of FEV1/FVC are indicators of strong respiratory function that deteriorate due to a sedentary lifestyle [7], decline of ventilatory functions in elderly people lead to decrease their ability to perform the daily activities and impair 
quality of life [1], so this population need therapeutic interventions to improve performance of the extremities which has a close relationship with ventilatory functions.

Exercise is a stressful condition which produces a marked change in body functions and lungs, and it improves the patient's functional and physiological status [8]. FVC is significantly improved after aerobic exercise [9]. Therefore, participation in certain physical activities or sports may lead to the strengthening of respiratory muscles, improvements in ventilatory functions, and achieving an effective ventilatory function (FVC, FEV1) [10,11]

The performance of many everyday tasks requires use of not only the hands, but also other muscle groups that are used in upper torso and arm positioning, some of these muscle groups serve respiratory as well as postural functions, so arm exercise can improve ventilation [12]. If the arms are trained to perform more work, or if the ventilatory requirement for the same work is decreased. Moreover, the capacity to perform activities of daily living could improve with parallel increase in strength and endurance of respiratory muscles and so decreased oxygen uptake at the same workload $[13,14]$.

Cycling (CYC) training improves ventilatory function and prevents respiratory disease, improves the endurance and strength of respiratory muscles, decrease resistance and increase lung elasticity and alveolar expansion by promoting the expansion of pulmonary volumes and capacities, and facilitates muscle strength/power [15], and cardiorespiratory fitness in older people [16]

Many of previous studies showed the effect of lower limbs aerobic training on ventilatory functions and ignoring the effect of upper limbs aerobic training, so the aim of our study to compare between the effect of upper versus lower limbs aerobic training on ventilatory function in elderly men which not clarified previously.

\section{Subjects and Methods}

Forty volunteers' elderly men had been enrolled in this study; they had been recruited from Outpatient Clinic of Faculty of Physical Therapy, Cairo University, Egypt. They were received their treatment program from april 2020 to February 2021, Patients had been divided into two groups equal in number; the group (A) performed upper limbs aerobic training by arm ergometer, while the group (B) performed lower limbs aerobic training by cycle ergometer. All subjects fully understood the purpose and methods of the study, which complied with the ethical standards. This study had approval of the Ethics Committee of Faculty of Physical Therapy, Cairo University, NO: P.T.REC/012/ 003201 Egypt. Written informed consent was obtained from each participant. Included and excluded of participants were according to the following criteria.

Inclusion criteria: Forty elderly subjects, Age ranged from (55-65) years old, BMI ranged between $25-34.9 \mathrm{~kg} / \mathrm{m}^{2}$ (overweight and class 1 obesity), All of the elderly did not receive any physical therapy programs related to respiratory training before they were participating in the study.

Exclusion criteria: Smokers' participants, Renal diseases, Liver diseases, Morbid obesity, Uncontrolled diabetes, Uncontrolled hypertensive subjects, Neurological dysfunction as cerebral stroke, Parkinsonism, neuropathy or psychological or mental impairments, Severe chronic cardiac problems, Chest diseases.

\section{Randomization:}

The participants were randomly assigned to group (A) $(n=20)$ and group (B) $(n=20)$ by an independent person who selected blindly from sealed envelopes containing numbers created by a random number generator. The randomization was restricted to permuted blocks to ensure that equal numbers were allocated to each group $\mathrm{A}$ and group $\mathrm{B}$. The sequences assigned to the participants were placed in enveloped containing the allocation to each group. The aim and procedures of the study were informed to eligible patients.

\section{Measures and equipment:}

A- Evaluating equipment: Electronic spirometer: Ventilatory function machine semi-new brand model trans/flow, Italy, to measure ventilatory function test pre and post intervention included the following. FEV1, FVC, FEV1/FVC ratio.

Body weight and height scale: Medical Equipment Folding Portable Weight and Height BMI Analyzer Health Measurement Equipment Scale, Mercury sphygmomanometer \& pulse oximeter:KBM blood Pressure Measuring Device Model Number: Sm300.

B- Training equipment: Arm Ergometer for upper limbs (Monark Rehab Trainer, Model 881E, made in Sweden), Cycle ergometer for lower limbs (Monark Rehab Trainer, Model 881E, made in Sweden). 
Preliminary assessment: Vital signs was measured and recorded initially then before and after each session through the training program, and BMI was calculated [17].

Ventilatory functions test: The items to be measured in the experiment were FVC, FEV1, FEV1/ FVC; ventilatory function tests were taken while the subjects were in a straight sitting posture on a chair. The subject's waist and shoulders were straight. Legs were opened to the width of the subject's shoulders, and feet were placed vertically on the floor [18]. Determination of exercise intensity of both groups: Submaximal exercise test to determine target heart rate (T.H.R) which $=85 \%$ of heart rate maximum (HRMAX) had been estimated by applying the formulae $211-0.64 \mathrm{x}$ age [19]. The low-intensity exercise at warm up and cooling down phase, The moderate-intensity exercise target heart rate's (THR) was 60\%-75\% from HRMAX, Frequency: 3 times/week for 12 weeks, Time of session: warm up and cooling down: 10min for each, Target heart phase time: $20 \mathrm{~min}$ with the initial 6 weeks, then progressed to 30min with last 6 weeks.

Instrument preparation: It has the ability for individual calibration according to each subject. Crank arms had been individually adjustable according to the subject height in order to be comfortable starting at horizontal level arm position 90 degrees shoulder elevation, Wooden Bars of different weights that were designed with hand grip in the middle third of the bar were used for comfortable grasping during the exercise [19]

Training procedures for group A (arm ergometer): After warming up exercise with no resistance (0 watts), during the conditioning phase the resistance was increased by 5 watts every one minute until the subject reached to calculated THR for 20 minutes. Then, the resistance was decreased to 0 watt to terminate the session with cooling down [20].

Training procedures for group B (cycle ergometer): The exercise started by warming up. During the conditioning phase the resistance was increased until the participants reached to THR for $20 \mathrm{~min}$ utes. Then, the resistance was decreased to 0 watt to terminate the session with cooling down [21].

Statistical analysis: After collecting data, statistical analysis was performed using SPSS statistical software, version 25 (IBM, Chicago, Illinois, USA). The normality of the data was confirmed by Shapiro-Wilk test, $(p>0.05)$. Baseline characteristics between the two groups (arm ergometer training and cycle ergometer training) were compared using Independent Samples $t$-test. Dependent and independent samples $t$-tests were used to investigate the changes in variables between pre and post-intervention and the differences between the two groups pre and post intervention, respectively. $p$-values less than or equal to 0.05 were considered statistically significant.

\section{Results}

\section{Demographic characteristics of the study:}

The present study included a total of 40 elderly males' patients; their mean age was $61.85 \pm 1.83$ years, and the mean BMI was $29.47 \pm 5.99 \mathrm{~kg} / \mathrm{m} 2$. Twenty patients acted as a group (A) and received arm ergometer training, while the remaining 20 patients were allocated as a group (B) and received cycle ergometer training.

There were no statistically significant differences between the two groups in terms of age, BMI, and ventilatory function (FEV1, FVC, FEV1/FVC, ) at baseline ( $p>0.05)$ (Table 1).

Table (1): Baseline characteristics of study participants $(n=40)$.

\begin{tabular}{|c|c|c|c|c|}
\hline Characteristics & Group A $(n=20)$ & Group B $(n=20)$ & $p_{\text {Indep. } t \text {-test }}$-value & Significance \\
\hline $\begin{array}{l}\text { Age (Years): } \\
\quad \text { Mean } \pm \text { SD }\end{array}$ & $62.05 \pm 1.67$ & $61.65 \pm 2.01$ & 0.497 & N.S \\
\hline $\begin{array}{r}B M I\left(k g / m^{2}\right): \\
\text { Mean } \pm \text { SD }\end{array}$ & $28.87 \pm 3.03$ & $30.08 \pm 7.99$ & 0.530 & N.S \\
\hline $\begin{array}{r}F E V I(L / S e c): \\
\text { Mean } \pm \text { SD }\end{array}$ & $2.08 \pm 0.72$ & $2.09 \pm 0.86$ & 0.991 & N.S \\
\hline $\begin{array}{l}F V C(L): \\
\quad \text { Mean } \pm \mathrm{SD}\end{array}$ & $2.57 \pm 0.62$ & $2.72 \pm 0.82$ & 0.529 & N.S \\
\hline $\begin{array}{c}F E V 1 / F V C(\%): \\
\quad \text { Mean } \pm \text { SD }\end{array}$ & $80.66 \pm 17.92$ & $71.92 \pm 17.78$ & 0.130 & N.S \\
\hline
\end{tabular}


There was a statistically significant increase in FEV1 (FEV1 increased from $2.08 \pm 0.72 \mathrm{~L} / \mathrm{Sec}$ to $2.57 \pm 0.62 \mathrm{~L} / \mathrm{Sec}$ in group (A) arm ergometer $\&$ and from $2.09 \pm 0.86 \mathrm{~L} / \mathrm{Sec}$ to $2.67 \pm 0.64 \mathrm{~L} / \mathrm{Sec}$ in group (B) cycle ergometer) and F.V.C (from $2.57 \pm 0.62 \mathrm{~L}$ to $3.16 \pm 0.68 \mathrm{~L}$ in group $\mathrm{A}$ ) arm ergometer and from $2.72 \pm 0.82 \mathrm{~L}$ to $3.41 \pm 0.80 \mathrm{~L}$ in group B cycle ergometer), between before and after 12 weeks of followup in both groups according to Paired Sample $t$ test $(p<0.05)$ (Table 2) and (Figs. 1,2). However, no significant difference was observed in the mean of FEV1/FVC ratio between pre and postintervention for 12 weeks in both groups $(p>0.05)$ (Table 2).

According to the Independent Sample $t$-test, there was no significant change in ventilatory function (FEV1, FVC, FEV1/FVC) between group (A) and group (B) after 12 weeks of follow-up $(p>0.05)$ (Table 2). So, we accept the null hypothesis that there was no significant difference between the effect of arm ergometer and cycle ergometer training on ventilatory function in elderly patients.

Table (2): Comparison of ventilatory function between before and after 12 weeks of intervention, in both groups.

\begin{tabular}{|c|c|c|c|c|c|c|c|c|c|}
\hline \multirow[b]{2}{*}{ Parameters } & \multicolumn{2}{|c|}{ Group A $(n=20)$} & \multirow{2}{*}{$\begin{array}{c}p_{\text {Paired }} \\
t \text {-test } \\
\text {-value }\end{array}$} & \multirow{2}{*}{$\begin{array}{c}\% \text { of } \\
\text { improvement }\end{array}$} & \multicolumn{2}{|c|}{ Group B $(n=20)$} & \multirow{2}{*}{$\begin{array}{c}\% \text { of } \\
\text { improvement }\end{array}$} & \multirow{2}{*}{$\begin{array}{c}p \text { Paired } \\
t \text {-test } \\
\text {-value }\end{array}$} & \multirow{2}{*}{$\begin{array}{c}p_{\text {Indep. }} \text {. } \\
t \text {-test } \\
\text {-value }\end{array}$} \\
\hline & $\begin{array}{c}\text { Pre- } \\
\text { intervention }\end{array}$ & $\begin{array}{l}\text { Post- } \\
\text { intervention }\end{array}$ & & & $\begin{array}{c}\text { Pre- } \\
\text { intervention }\end{array}$ & $\begin{array}{l}\text { Post- } \\
\text { intervention }\end{array}$ & & & \\
\hline FEV1 (L/Sec) & $2.08 \pm 0.72$ & $2.57 \pm 0.62$ & $0.001 * *$ & $23.56 \% \uparrow$ & $2.09 \pm 0.86$ & $2.67 \pm 0.64$ & $27.75 \% \uparrow$ & $0.000 * *$ & 0.629 \\
\hline FVC $(\mathrm{L})$ & $2.57 \pm 0.62$ & $3.16 \pm 0.68$ & $0.000 * *$ & $22.96 \% \uparrow$ & $2.72 \pm 0.82$ & $3.41 \pm 0.80$ & $25.37 \% \uparrow$ & $0.001 * *$ & 0.302 \\
\hline FEV1/FVC (\%) & $80.66 \pm 17.92$ & $81.51 \pm 13.15$ & 0.833 & $1.05 \% \uparrow$ & $71.92 \pm 17.78$ & $78.44 \pm 8.24$ & $9.07 \% \uparrow$ & 0.113 & 0.383 \\
\hline
\end{tabular}

FEV 1: Forced expiratory volume in the first second.

FVC : Forced vital capacity.

FEV 1/FVC: Ratio of Forced expiratory volume in the first second to Forced vital capacity.

Data represented as mean \pm standard deviation (SD).

$*$ : Statistically significant at $p \leq 0.05$ according to Independent Sample $t$-test.

**: Statistically significant at $p \leq 0.05$ according to Paired Sample $t$-test.

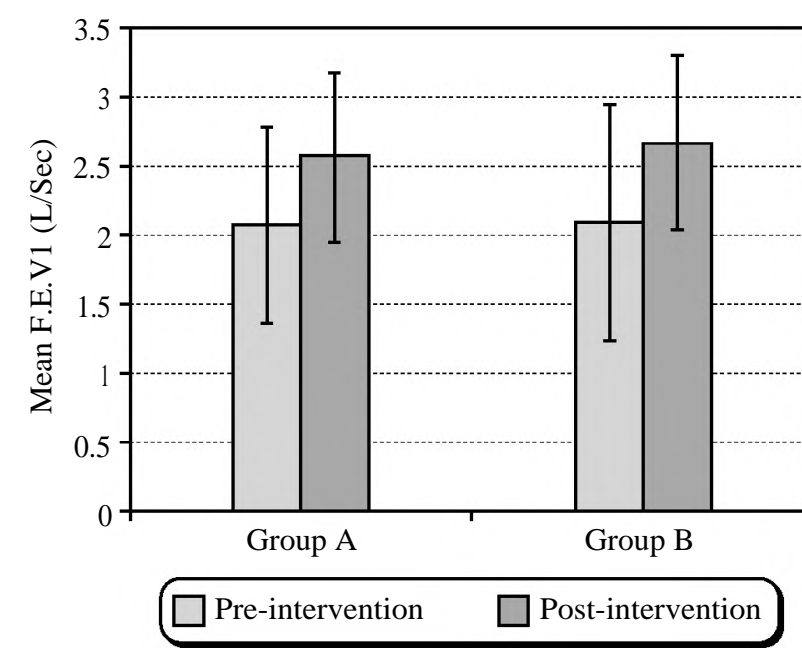

Fig. (1): Error bar chart showing the change in the mean of FEV $1(\mathrm{~L} / \mathrm{Sec})$ pre and post-intervention in both groups.

\section{Discussion}

In general, ventilator function declines with age [22]. Cycling (CYC) training facilitates muscle strength/power [23] and cardiorespiratory fitness in older people [14].

Pogliaghi [15] reported that arm crank exercise (ACE) and CYC training elicited similar "crosstransfer" training effects (i.e. improved fitness

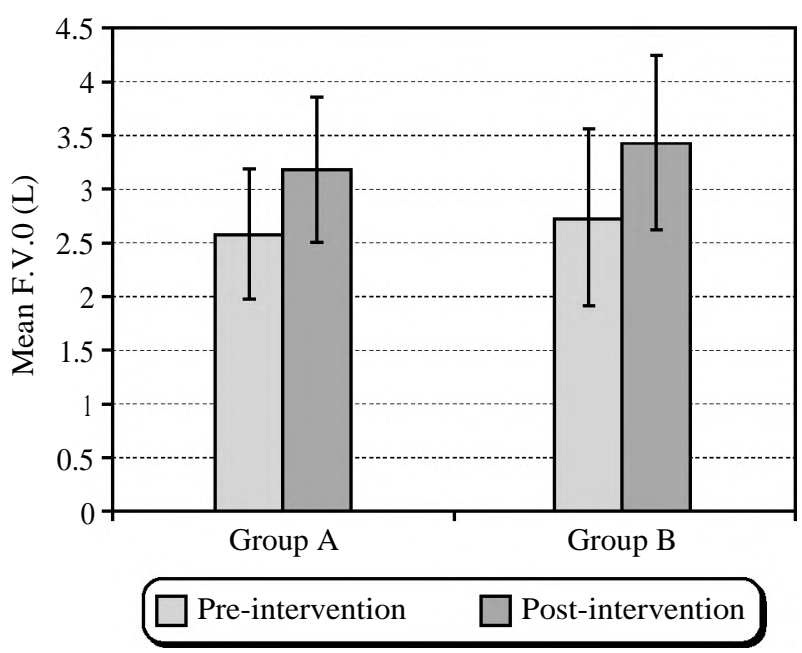

Fig. (2): Error bar chart showing the change in the mean of FVC (L) pre and post-intervention in both groups.

effect of ACE resulted in functional improvements during CYC and vice versa) among older adult and this support the study result that there was no significant difference between arm \& cycle ergometer.

Furthermore, the effect of closed kinematic chain training of arm using arm ergometer on dynamic lung volumes and flow rates; forced expiratory volume at first second showed significant 
improvement after closed kinematic chain training "supported arm exercise" which means arm ergometer) researched by Kandil et al. [17], and this support our study that found increase in FEV 1 and FVC in response to arm and cycle ergometer as in supported arm exercise, the arms are supported thus increasing the ventilatory contribution of the inspiratory muscles of the neck and rib cage decreasing the contribution by the diaphragm thus decreasing the ventilatory demand as well as oxygen demands allowing longer time for exercise.

Cycle ergometer training (CET) in this study improved ventilatory function such as FEV 1 and FVC and this supported with Lovell et al. [23] who found a significant increase in VO2max of CET on cardio-respiratory fitness (15 and $17 \%$ respectively, $p<0.05$ ) among older patients over 70 .

The results of this study came in agreement with the study of Park [12], who demonstrated that, aerobic exercise increased the oxygen uptake and activated inactive alveoli, and repeated stimulation of inspiration and expiration increased alveolar compliance. As a result, FVC increased. As more inactive alveoli were activated, more air could enter the alveoli, and increased alveolar compliance could be attributed to increased lung elasticity and more air expiration. FEV 1 is a typical index of resistance to air flow in the respiratory tract.

Ratio of F.E.V1/F.V.C had no significant difference in our study as in our study there is increase in one variable only or two variables which was previously decreased so decrease ratio, and this contradict with the study of Song and Kim, 2016 [24], who researched the effect of exercise on FEV1/FVC and reported that the enhancement of respiratory muscles and trunk muscles and the improvement of rib cage movement had a positive effect on FEV 1/FVC.

Lee et al. [9], who researched the effect of aerobic exercise on lower limbs on the maximumexpiratory lung capacity of elderly women. In the results, FVC significantly improved after aerobic exercise. In other words, vital capacity increased after high intensity aerobic exercise, that FVC is significantly improved after high-intensity aerobic exercise, like the increase that happened in response to arm cycle ergometer equally in our study to F.V.C.

Prakash et al. [25] and Mahotra et al. [10] reported that participation in certain physical activities or sports may lead to the strengthening of respiratory muscles, improvements in ventilatory functions, and achieving an effective ventilatory function (FVC, FEV1), like the increase that happened in response to arm cycle ergometer equally in our study to FVC \& FEV 1.

Moreover, the result of our study came in agreement with Farid et al. [26], who examined the effects of a course of aerobic exercise on ventilatory function and tolerance of activity in asthmatic patients. They founded that a course of aerobic sport exercise causes an obvious increase in FEV 1, FVC, in asthmatic patients, and a regular aerobic sports program can be complementary to medical treatment in asthma rehabilitation.

Despite of our positive outcomes in this study, some limitations should be considered. First, based on subject selection criteria, results generalizability may be limited to other populations. Second, we applied only one exercise program so, we recommended further studies to evaluate the effect of different exercise programs and intensities on ventilatory functions in elderly people. Thus, our findings provide critical evidence on upper limbs training benefits comparing with lower limbs aerobic training in improving ventilatory functions and improving the quality of life older adult people.

Conclusion: Moderate intensity aerobic exercise on both arm ergometer and cycle ergometer had equal effect on the ventilatory function of elderly men. So we recommended further studies to determine the effect of upper limbs aerobic training on other health problems in elderly people.

\section{Acknowledgments:}

The authors thank all individuals participated in this study and we are grateful to Dr. Ebthall Mohamed for her contribution in biostatistics of this study.

\section{Authors' Contribution:}

All authors contributed equally to the whole research processes as conceptualization, data curation, investigation, methodology, project administration, resources, writing-review \& editing, read and approved the final version of the manuscript, and agree with the order of presentation of the authors.

\section{Funding/Support:}

The authors received no financial support for the research and publication of this article.

\section{Declaration of interest:}

The authors declare that there is no conflict of interest that could be perceived as prejudicing the impartiality of the research reported. 


\section{References}

1- SANADA F., TANIYAMA Y., MURATSU J., OTSU R., SHIMIZU H., RAKUGI H. and MORISHITA R.: Source of chronic inflammation in aging. Frontiers in Cardiovascular Medicine, Feb. 22; 5: 12, 2018.

2- SWEED H.S.: Population Ageing-Egypt Report. Middle East Journal of Age and Ageing, Dec. 13 (2): 10-7, 2016.

3- BOWLING A. and DIEPPE P.: What is successful ageing and who should define it?. BMJ, Dec. 22; 331 (7531): 1548-51, 2005.

4- NICCOLI T. and PARTRIDGE L.: Ageing as a risk factor for disease. Current Biology, Sep. 11; 22 (17): R741-52, 2012.

5- YÁÑEZ A., CHO S.H., SORIANO J.B., ROSENWASSER L.J., RODRIGO G.J., RABE K.F., PETERS S., NIIMI A., LEDFORD D.K., KATIAL R. and FABBRI L.M.: Asthma in the elderly: What we know and what we have yet to know. World Allergy Organization Journal, Dec. 7 (1): 1-6, 2014.

6- SORINO C., BATTAGLIA S., SCICHILONE N., PEDONE C., ANTONELLI-INCALZI R., SHERRILL D. and BELLIA V.: Diagnosis of airway obstruction in the elderly: Contribution of the SARA study. International journal of chronic obstructive pulmonary disease, 7: 389 , 2012.

7- LOMBARDI I., OLIVEIRA L.M., MAYER A.F., JARDIM J.R. and NATOUR J.: Evaluation of pulmonary function and quality of life in women with osteoporosis. Osteoporosis International, Oct. 16 (10): 1247-53, 2005.

8- THAMAN R.G., ARORA A. and BACHHEL R.: Effect of physical training on pulmonary function tests in border security force trainees of India. Journal of Life Sciences, Jul. 1; 2 (1): 11-5, 2010.

9- LEE J.Y., JUNG J.H., CHUNG E.J. and KIM K.: The effect of feedback breathing exercise and treadmill exercise on chest length and pulmonary function of the middleaged. Journal Special Education Rehabilitation Science, 52: 319-33, 2013.

10- MAHOTRA N.B., AMATYA T.M., RANA B.S. and BANSTOLA D.: Effects of exercise on pulmonary function tests: A comparative study between athletes and nonathletes in Nepalese settings. Journal of Chitwan Medical College, 6 (1): 21, 2016.

11-ERICKSON K.I., VOSS M.W., PRAKASH R.S., BASAK C., SZABO A., CHADDOCK L., KIM J.S., HEO S., ALVES H., WHITE S.M. and WOJCICKI T.R.: Exercise training increases size of hippocampus and improves memory. Proceedings of the National Academy of Sciences, Feb. 15; 108 (7): 3017-22, 2011.

12- PARK J. and HAN D.: Effects of high intensity aerobic exercise on treadmill on maximum-expiratory lung capacity of elderly women. Journal of Physical Therapy Science, 29 (8): 1454-7, 2017.

13- LOVELL D.I., CUNEO R. and GASS G.C.: The effect of strength training and short-term detraining on maximum force and the rate of force development of older men. European Journal of Applied Physiology, Jun. 109 (3): 429-35, 2010
14- OJA P., TITZE S., BAUMAN A., De GEUS B., KRENN P., REGER-NASH B. and KOHLBERGER T.: Health benefits of cycling: A systematic review. Scandinavian journal of medicine \& science in sports, Aug. 21 (4): 496$509,2011$.

15- POGLIAGHI S., TERZIOTTI P., CEVESE A., BALESTRERI F. and SCHENA F.: Adaptations to endurance training in the healthy elderly: arm cranking versus leg cycling. European Journal of Applied Physiology, Aug. 97 (6): 723-31, 2006.

16- HAN J.W. and KIM Y.M.: Effect of breathing exercises combined with dynamic upper extremity exercises on the pulmonary function of young adults. Journal of back and musculoskeletal rehabilitation, Jan. 1; 31 (2): 405-9, 2018.

17- KANDIL O.A. and HAMED H.M.: Selected Ventilatory Functions Response to Closed and Open Kinematic Chain training of the arm in elderly. Life Science Journal, 8 (2), 2011.

18- HAN D., YOON N., JEONG Y., HA M. and NAM K.: Effects of cervical self-stretching on slow vital capacity. Journal of Physical Therapy Science, 27 (7): 2361-3, 2015.

19- AL HADDAD H., LAURSEN P.B., CHOLLET D., AHMAIDI S. and BUCHHEIT M.: Reliability of resting and postexercise heart rate measures. International Journal of Sports Medicine, May 13; 32 (8): 598, 2011.

20- HELAL M.H., SALEM M.A., EL-GABY M.S. and ALJAHDALI M.: Synthesis and biological evaluation of some novel thiazole compounds as potential antiinflammatory agents. European Journal of Medicinal Chemistry, Jul. 1; 65: 517-26, 2013.

21- SOLIMAN G.S. and ABDELBASSET W.K.: Efficacy of aerobic training on pulmonary functions and depression in elderly COPD patients. Journal of Advanced Pharmacy Education \& Research, Oct-Dec. 9 (4), 2019.

22- LEE B., PARK S. and HAN D.: Analysis of the influential factors of maximal-effort expiratory capacity of elderly women. Journal of Physical Therapy Science, 28 (10): 2924-8, 2016

23- LOVELL D.I., CUNEO R., WALLACE J. and McLELLAN C.: The hormonal response of older men to submaximum aerobic exercise: The effect of training and detraining. Steroids, Apr. 1; 77 (5): 413-8, 2012.

24- SONG J.W. and KIM G.D.: Effects of core stability training on the pulmonary function and trunk muscle activity in chronic stroke patients. Asia-pacific Journal of Multimedia Services convergent with Art. Humanity Soc., 6: 101-8, 2016.

25- PRAKASH S., MESHRAM S. and RAMTEKKAR U.: Athletes, yogis and individuals with sedentary lifestyles; do their lung functions differ?. Indian Journal of Physiology and Pharmacology, Jan. 20; 51 (1): 76, 2007.

26- FARID R., AZAD F.J., ATRI A.E., RAHIMI M.B., KHALEDAN A., TALAEI-KHOEI M., GHAFARI J. and GHASEMI R.: Effect of aerobic exercise training on pulmonary function and tolerance of activity in asthmatic patients. Iran Journal allergy Asthma Immunol., Sep. 4 (3): 133-8, 2005. 


\section{استجابة الوظائف التثفسية للتدريبات الهوائية لاطراف العلوية العافية

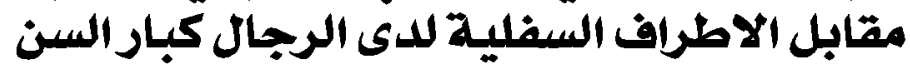

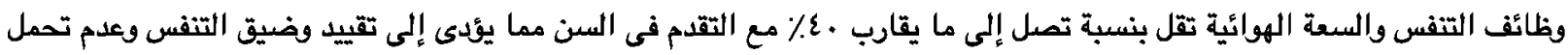

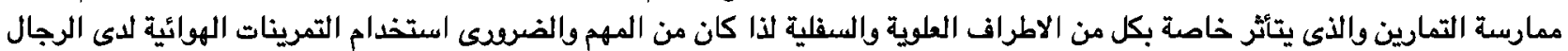

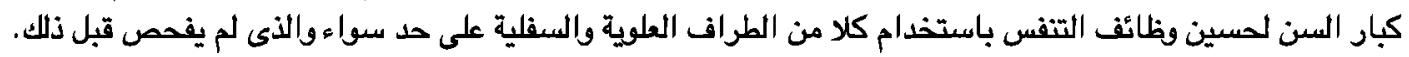

الهدف من الدراسة: المقارنة بين تأثر التمارينات الهوائية باستخدام الاطراف العلوية مقابل الاطراف السفلية وتأثر ذلك على وظائف التنفس

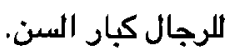

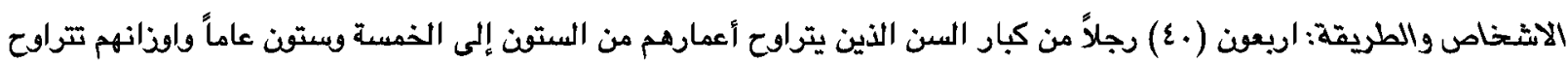

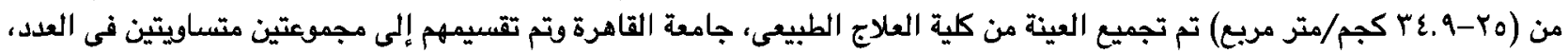

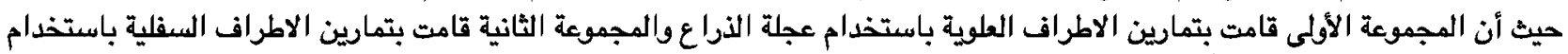

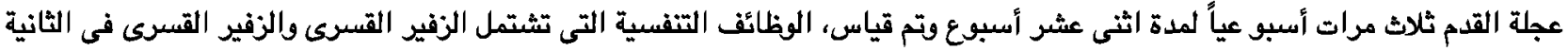
الأولى والنسبة بينهما قبل بدء ونهاية الدراسة.

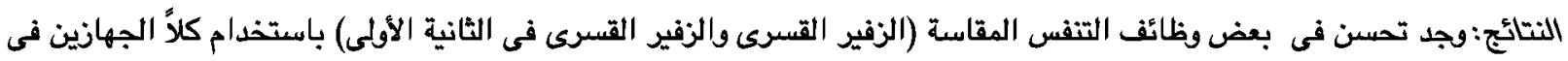

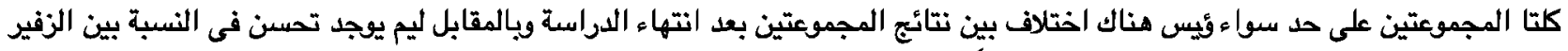

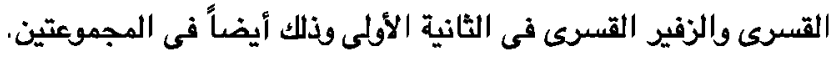

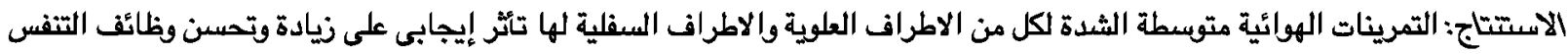

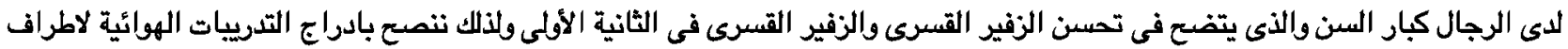
الطوية فر برامج التأهيل التنفسى لكبار السن. 